\title{
Data mining, fuzzy AHP and TOPSIS for optimizing taxpayer supervision
}

\author{
M. Jupri ${ }^{1}$, Riyanarto Sarno ${ }^{2}$ \\ ${ }^{1}$ Department of Information Technology Management, Faculty of Business and Technology Management, \\ Institut Teknologi Sepuluh Nopember, Indonesia \\ ${ }^{2}$ Department of Informatics, Faculty of Information Technology and Communication, \\ Institut Teknologi Sepuluh Nopember, Indonesia
}

\begin{tabular}{l}
\hline \hline Article Info \\
\hline Article history: \\
Received Jul 30, 2019 \\
Revised Sep 3, 2019 \\
Accepted Oct 8, 2019 \\
\hline
\end{tabular}

Keywords:

Data mining

Fuzzy AHP

Taxpayer compliance

Taxpayer supervision

TOPSIS

\begin{abstract}
The achievement of accepting optimal tax need effective and efficient tax supervision can be achieved by classifying taxpayer compliance to tax regulations. Considering this issue, this paper proposes the classification of taxpayer compliance using data mining algorithms; i.e. C4.5, Support Vector Machine, K-Nearest Neighbor, Naive Bayes, and Multilayer Perceptron based on the compliance of taxpayer data. The taxpayer compliance can be classified into four classes, which are (1) formal and material compliant taxpayers, (2) formal compliant taxpayers, (3) material compliant taxpayers, and (4) formal and material non-compliant taxpayers. Furthermore, the results of data mining algorithms are compared by using Fuzzy AHP and TOPSIS to determine the best performance classification based on the criteria of Accuracy, F-Score, and Time required. Selection of the taxpayer's priority for more detailed supervision at each level of taxpayer compliance is ranked using Fuzzy AHP and TOPSIS based on criteria of dataset variables. The results show that $\mathrm{C} 4.5$ is the best performance classification and achieves preference value of 0.998 ; whereas the MLP algorithm results from the lowest preference value of 0.131 . Alternative taxpayer A233 is the top priority taxpayer with a preference value of 0.433 ; whereas alternative taxpayer A051 is the lowest priority taxpayer with a preference value of 0.036 .
\end{abstract}

Copyright $\odot 2020$ Institute of Advanced Engineering and Science. All rights reserved.

\section{Corresponding Author:}

Riyanarto Sarno,

Department of Informatics,

Faculty of Information Technology and Communication,

Institut Teknologi Sepuluh Nopember, Surabaya, Indonesia.

Email: riyanarto@if.its.ac.id

\section{INTRODUCTION}

Tax is the largest state income to finance government administration, public services, and public infrastructure [1]. Because taxes are very important for the state, tax authorities must know all types of tax evasion, both by individual taxpayers and corporate taxpayers in Indonesia, quickly, effectively and efficiently. The taxation system in Indonesia is a self-assessment system. It means taxpayer calculates, deposits and self-reports the amount of tax he/she should pay based on the tax laws and regulations.

The consequence of self-assessment taxation system in Indonesia is a big data which comes from Periodic Tax Return and Annual Tax Return. It requires an effective and efficient way to be managed based on tax regulations. Effective means the tax authorities supervise taxpayers based on the compliance classification and determine taxpayers priorities based on predetermined variable criteria. Efficient means the tax authorities supervise taxpayers so that taxpayers do tax obligations based on the tax regulations without 
much time and big effort. Furthermore, taxes are forced by obtaining indirect compensations; thus, taxpayers tend to avoid tax or try to do tax evasion. It will harm the state in the form of reduced tax revenues.

Several studies related researches to detect tax avoidance efforts have been conducted. The researchers [2], conducted a study developing a system that can measure the dimensions of billboards without physically touching them automatically to calculate tax in Indonesia. The researchers [3], conducted a study using a hybrid intelligence system to detect tax evasion from corporate taxpayers, namely taxpayers who do business beverages and textile in Iran. The researchers [4], conducted a study investigating classic tax evasion cases using several methods aimed at classifying tax evasion behavior based on the network that has been simulated with real data. The researchers [5], conducted a study by applying parallelism techniques that aim to improve the performance of fraud detection algorithms. Another researchers [6], conducted a study to detect fraudulent tax invoices using various types of data mining techniques.

This study proposes taxpayer supervision which variables in this study can be used for all types of taxpayers in Indonesia and can be used for all types of tax in Indonesia. Each state has different tax regulations and administration, so this study has advantages compared to other studies because this study detect tax avoidance in Indonesia. The supervision of taxpayers in this study is to classify taxpayer compliance into four classes with the classification algorithms of data mining. The classification algorithms chosen are C4.5, Support Vector Machine (SVM), K-Nearest Neighbor (KNN), Naive Bayes (NB), and Multilayer Perceptron (MLP). Every algorithm is compared to determine the best performance classification using Fuzzy AHP and TOPSIS. The best performance classification is chosen based on the criteria of Accuracy, F-Score and Time required. The priorities of taxpayers compliance supervision are formal and material non-compliant taxpayers, formal compliant taxpayers, material compliant taxpayers, and formal and material compliant taxpayers. Every taxpayer's compliance has a lot of data. Therefore, it has to priority taxpayers to be examined and processed based on tax regulations. In determining the priority of taxpayers, researchers propose fuzzy AHP and TOPSIS methods. The results show that alternative taxpayer A233 is the top priority taxpayer with a preference value of 0.433 ; whereas alternative taxpayer A051 is the lowest priority taxpayer with a preference value of 0.036 .

\section{RESEARCH METHOD}

This study proposes effective and efficient taxpayer supervision by classifying taxpayer compliance into four classes. In general, the flow of this study is explained in Figure 1.

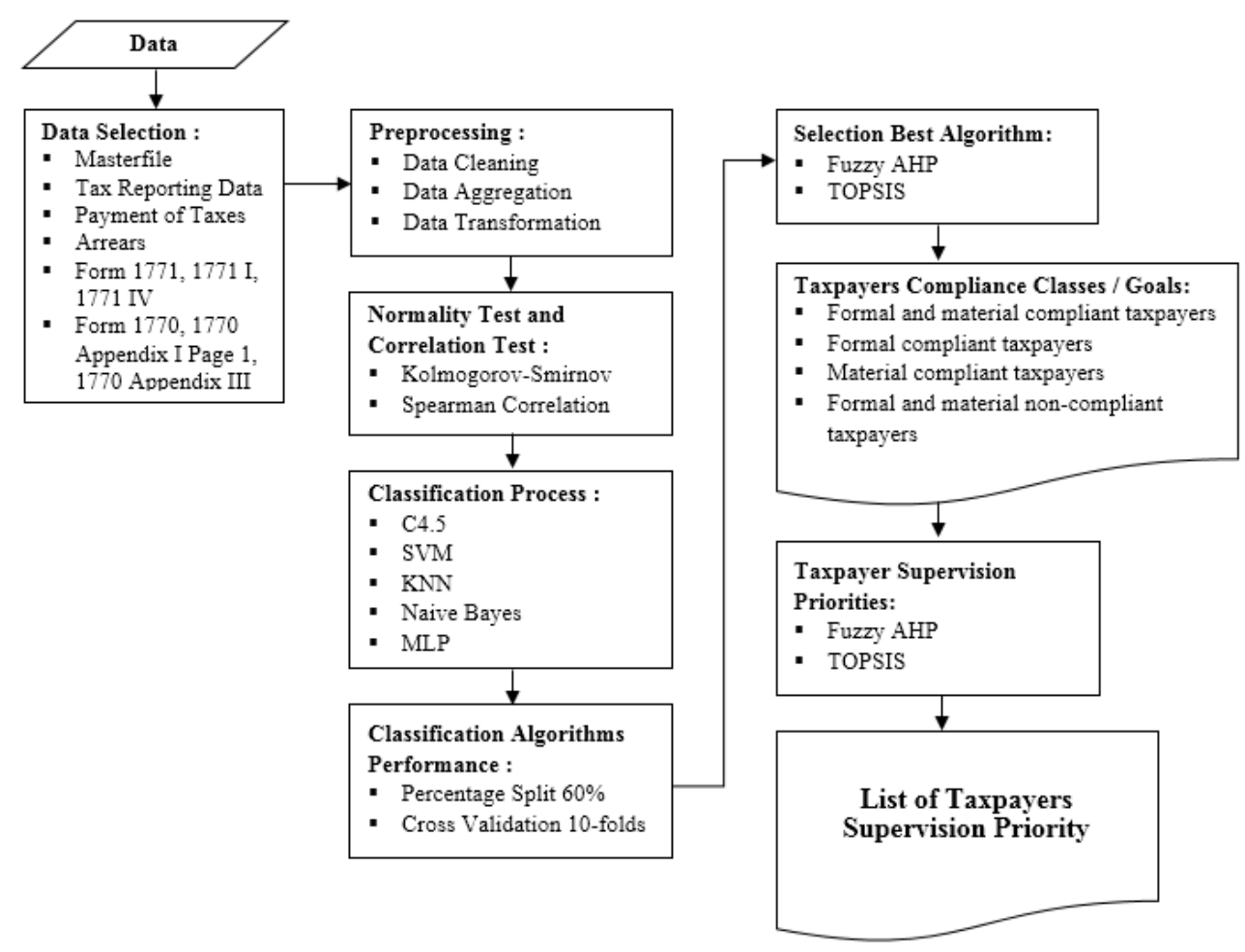

Figure 1. General description of the overall study 


\subsection{Selection Data}

Data mining is the process of finding patterns and trends from large data so that predictions can be made about that data [7,8]. Selection of variables in data mining is the process of identifying some of the most important variables or attributes that are important in the model for goals prediction [9]. This study uses data sources from the reporting of certain regional taxpayers for the 2015-2017 tax years. Tables from the database used are Masterfile of taxpayers, Tax Reporting Data, Tax Payments, Arrears, Form 1771, 1771 I, 1771 IV, Form 1770, 1770 Appendix I Page 1, and 1770 Appendix III.

\subsection{Preprocessing}

Preprocessing is a step doing to make raw data into quality data [10]. The data is cleaned to correct bad data, filtering some incorrect data from the dataset and reducing unnecessary data details [10]. Data aggregation is the preprocessing process to summarize data [11]. Variables from the data aggregation process are Late_Report, Not_Report, Late_To_Pay, GPM, NPM and CTTOR. Late_Report and Not_Report variables are accumulations of late reports and unreported amounts in one tax year derived from tax reporting tables. Gross Profit Margin (GPM), Net Profit Margin (NPM), and Corporate Tax Turn Over Ratio (CTTOR) variables are financial ratio analysis variables. The Taxable Entrepreneur variable (PKP) is the result of transforming the PKP date column in the masterfile of taxpayers table where "Yes" if the PKP date is not null and "No" if the PKP date is null. Data Transformation is the process of consolidating data into forms that are suitable for data mining purposes [11]. The formal and material compliant taxpayers come from the list of compliant taxpayers with the criteria for late reporting within a year no more than three times, not reporting in a year no more than three times and late paying in one year no more than three times. Goals come from data on taxpayers who make corrections to Tax Return or taxpayers are issued Tax Underpayment Assessment Letter (SKPKB).

\subsection{Normality Test and Correlation Test}

This study uses the Kolmogorov-Smirnov normality test to find the distribution of data normal or not. The normality test determines the correlation test method to select dataset variables. The Kolmogorov Smirnov normality test compares the distribution data with normal distribution standard [12]. The data is not normal if the significance is below 0.05 [13]. The Kolmogorov-Smirnov test in this study used the SPSS Statistic 23 tool and the results showed that the study data had an abnormal distribution so that the correlation test method used the Spearman correlation.

The correlation test serves to select and to ensure the variables correlate with the goals to be achieved. The Spearman correlation test is a nonparametric statistic and it is used in the condition of one or both variables measured are ordinal scale or both variables are quantitative, but normal conditions are not met [14]. The Spearman correlation test in this study uses the SPSS Statistic 23 tool to determine the strength level of the inter-variable relationship guided by the correlation coefficient value. The correlation coefficient value is $0.00-0.25=$ little or no relationship, correlation coefficient value is $0.25-0.50=$ fair degree of relationship, correlation coefficient value is $0.50-0.75=$ moderate to good relationship, and correlation coefficient value is $>0.75$ = very good to excellent relationship [14].

\subsection{Classification Process}

The classification process is the process of analyzing data by extracting a model that describes important data classes [11]. The process of classification data is divided into two steps, which consist of learning steps (where the classification model is built) and the classification step (where the model is used to predict goals based on the data given) [11]. The dataset has been created, using the C4.5, SVM, KNN, NB, and MLP classification algorithms to see the best performance classification.

C4.5 is a classification algorithm of data mining processes by forming a decision tree [15]. The first step this algorithm calculates information gain of all the attributes and then selects the root node from attribute having the highest information gain (1). The gain value can be calculated by finding the entropy value first (2). Entropy is diversity.

$$
\operatorname{Gain}(y, A)=\operatorname{Entropy}(y)-\sum_{C \in \operatorname{value}(A)} \frac{y_{c}}{y} \operatorname{Entropy}\left(y_{c}\right)
$$

where value $(A)$ is all possible values of attribute $\mathrm{A}$, and $y_{c}$ is a subset of $y$ where $A$ has a value of c

$$
\operatorname{Entropy}(y)=\sum_{i=1}^{n}-p_{i} \log _{2} p_{i}
$$

where $p_{1}, p_{2}, \ldots, p_{n}$ each express the proportions of class 1 , class $2, \ldots$, class $n$ in output $y$. 
The second step makes a branch based on the possible attribute values, then divide the case into branches, and this process is repeated for each new branch so that the case in the branch has the same class. Support Vector Machine is a supervised learning model for conducting a linear and non-linear classification of data [16, 17]. The SVM method finds the optimal hyperplane that separates feature points from two different classes with the largest margin possible in the feature space. Classification cases are linearly separable, the separating function sought is a linear function using (3).

$$
g(x)=\operatorname{sign}(f(x))
$$

with $f(x)=w^{T} x+b$, where $x, w, b \in R$. This classification problem can be formulated as follows: we find the set of parameters $(w, b)$ so that $f\left(x_{i}\right)=\left\langle w, x_{i}\right\rangle+b=y_{i}$ for all i. This technique finds the best separator function between functions that are not limited to separating two objects. If in two dimensions the separator is a line, in three dimensions the separator is a plane, and in high dimensions (more than three) the separator is a hyperplane. The best hyperplane is a hyperplane located in the middle between two sets of objects from two classes. Finding the best hyperplane is equivalent to maximizing the margin, which is the distance between the hyperplane and the support vectors.

K-Nearest Neighbor is a supervised algorithm learning based on the k-nearest neighbor by classifying new instances based on the majority of the k-nearest neighbor categories [18]. This method calculates similarities between samples of unlabeled data and all training data samples [19]. KNN is determined by looking at the shortest distance from the query instance to the training sample data. The Euclidean distance formula is often used to determine the distance between two training and testing objects.

Naive Bayes is a classification method based on the application of the Bayes theorem using knowledge about probability and statistics [20]. The Naive Bayes algorithm predicts future opportunities based on previous experience so that it is known as the Bayes Theorem (4). The main characteristic of Naïve Bayes Classifier is a very strong (naïve) assumption of independence from each condition/event.

$$
\mathrm{P}(\mathrm{C} \mid \mathrm{X})=\frac{\mathrm{P}(\mathrm{X} \mid \mathrm{C}) \mathrm{P}(\mathrm{c})}{\mathrm{P}(\mathrm{x})}
$$

where $\mathrm{x}$ is data with an unknown class, $\mathrm{c}$ is the data hypothesis is a specific class, $\mathrm{P}(\mathrm{c} \mid \mathrm{x})$ is probability of hypothesis based on condition (posterior probability), $\mathrm{P}(\mathrm{c})$ is probability of hypothesis (prior probability), $\mathrm{P}(\mathrm{x} \mid \mathrm{c})$ is probability based on conditions on the hypothesis, and $\mathrm{P}(\mathrm{x})$ : Probability c.

Multilayer Perceptron adopts the workings of neural networks in living things, namely having an architecture on how to convert two or more inputs into output [21]. The inspiration of ANN comes from the observation that the system of learning from living things, especially humans, from very complex networks consisting of interconnected neurons. ANN appears as an alternative to conventional approaches which are usually less flexible about structural changes in problems. ANN proposes the advantages of being able to get over several problems without making drastic changes to the model.

\subsection{Classification Algorithms Performance}

Confusion matrix, Percentage Split Test, and k-fold Cross-validation have a function to determine the performance of the C4.5, SVM, KNN, NB, and MLP classification algorithms in classifying dataset based on goals of this study.

The confusion matrix is the process of evaluating the performance of a system by determining the amount of data that is classified correctly and incorrectly [22, 23]. The table confusion matrix shows the relationship between observed and estimated values for evaluating data classification results [24]. Accuracy is a comparison between data classified correctly with all data tested (5). Precision describes the number of positive category data that are classified correctly divided by the total data classified as positive (6). Recall shows what percentage of positive category data is correctly classified by the system (7). F-score is a combination of Precision and Recall to measure the main quality and can be used as an alternative (7).

$$
\begin{aligned}
\text { Accuracy } & =\frac{(\mathrm{TP}+\mathrm{TN})}{(\mathrm{TP}+\mathrm{TN}+\mathrm{FP}+\mathrm{FN})} \\
\text { Precision } & =\frac{\mathrm{TP}}{(\mathrm{TP}+\mathrm{FP})} \\
\text { Recall } & =\frac{\mathrm{TP}}{(\mathrm{TP}+\mathrm{FN})}
\end{aligned}
$$

Indonesian J Elec Eng \& Comp Sci, Vol. 18, No. 1, April 2020 : 75 - 87 


$$
\text { F-Score }=\frac{(2 \times \text { Precision } \times \text { Recall })}{(\text { Precision }+ \text { Recall })}
$$

where TP is True Positive, TN is True Negative, FP is False Positive, and FN is False Negative.

Percentage Split Test divides the test method into two, training sets and test sets based on the desired percentage (Figure 2) [25]. The K-fold Cross-validation method divides the dataset consisting of training data as many as k-1 and testing data as many as 1 . This study uses the value of k 10 (Figure 2) [26]. This study, the results of value of accuracy, F-Score, and Time required (Time) from Percentage Split Test method and K-fold Cross-validation method are searched the average value of each classification algorithm where is the average results as a basis for calculating the Alternative Data Normalization Matrix in TOPSIS method for determining algorithm with the best performance classification.
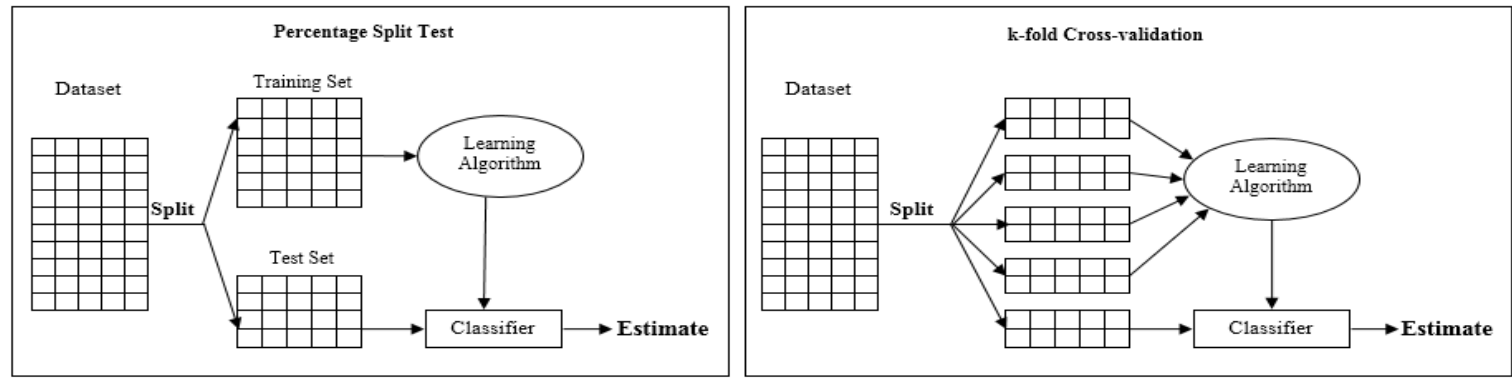

Figure 2. Algorithms testing methods

\subsection{Selection Best Algorithm}

Accuracy, F-Score, and Time required are the criteria for determining the best performance classification algorithm. The criteria were given weights with Fuzzy AHP and were ranked using TOPSIS. Fuzzy AHP functions to determine the weight of the specified criteria and TOPSIS to rank the selected alternatives [27]. This study uses Fuzzy AHP and TOPSIS because this method can provide good results and this method is suitable for solving complex problems that are not too subjective [28]. Figure 3 is the hierarchy to determine the best performance classification algorithm in this study.

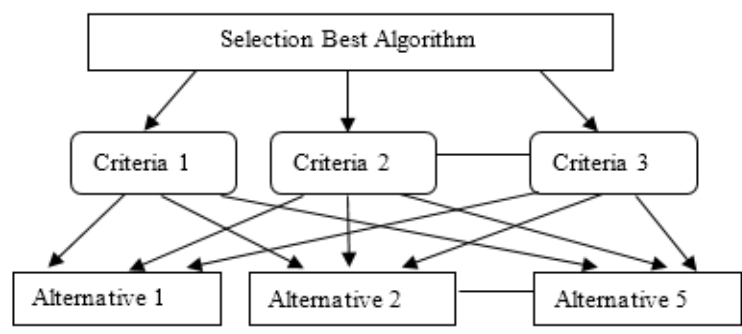

Figure 3. Hierarchy of purpose selection best algorithm

Fuzzy AHP method combines Analytic Hierarchy Process (AHP) and Fuzzy functions to minimize the obscurity that is formed in the fuzzy ratios [29]. Fuzzy AHP combines the AHP ranking with a fuzzy concept approach [30]. Fuzzy AHP is used to improve the deficiency of the AHP method, namely to solve problems that are not too subjective. AHP method is used to help solve multi-criteria problems from several alternative decisions [31-33]. AHP method solves the problem by breaking the problem into several parts so that it forms a hierarchy of three parts of objectives, criteria and alternatives [34, 35]. To get better results, AHP is combined with other techniques such as Fuzzy logic [36].

The Fuzzy set approach in AHP has the purpose of solving the problem of obscurities of human thought that was first used by Zadeh [37, 38]. Fuzzy numbers make it possible to solve the problems where criteria are not precisely defined [39]. To solution this, a number of special Triangular Fuzzy Numbers (TFN) were formed into AHP values which are divided into three parts, namely $1=$ lowest value, $\mathrm{m}=$ middle value and $\mathrm{u}=$ highest value, using (9) [40, 41]: 


$$
\mu_{T}(x)=\left\{\begin{array}{c}
\frac{x-l}{m-l}, \text { if } x \in[l, m] \\
\frac{u-x}{u-m}, \text { if } x \in[m, u] \\
0, \text { otherwise }
\end{array}\right.
$$

The first steps of Fuzzy AHP create the hierarchical structure of the problem that must be solved and determine the comparison of the paired matrices between the criteria and the scale of the TFN. The next steps determine the value of fuzzy Synthesis ( $\mathrm{Si}$ ) using (10).

$$
S_{i}=\sum_{j=1}^{m} M^{j} g_{i} \otimes\left[\sum_{i=1}^{n} \sum_{j=1}^{n} M^{j} g_{i}\right]^{-1}
$$

where: $\sum_{j=1}^{m} M^{j} g_{i}$ is the sum of each TFN value in a paired matrix (11)

$$
\sum_{j=1}^{m} M^{j} g_{i}=\left(\sum_{j=1}^{m} l_{j}, \sum_{j=1}^{m} m_{j}, \sum_{j=1}^{m} u_{j}\right)
$$

while $\left[\sum_{i=1}^{n} \sum_{j=1}^{n} M^{j} g_{i}\right]^{-1}$ is the inverse of the operation of the number of TFN (12)

$$
\left[\sum_{i=1}^{n} \sum_{j=1}^{n} M^{j} g_{i}\right]^{-1}=\left(\frac{1}{\sum_{i=1}^{n} u_{i}}, \frac{1}{\sum_{i=1}^{n} m_{i}}, \frac{1}{\sum_{i=1}^{n} l_{i}}\right)
$$

After the operational fuzzy continues, then the search process for the possible level of operational fuzzy continues. The probability level is assumed to be $M \_2 \geq M \_1$ where $M \_1=\left(1 \_1, \mathrm{~m} \_1, \mathrm{u} \_1\right)$ and $\mathrm{M} \_2=$ (1_2, m_2, u_2) for more details see (13).

$$
V\left(. M_{\cdot 2} \cdot \geq M_{.1}\right) \cdot=S U P_{y \geq x} \cdot\left[\cdot \min \cdot\left(\mu \cdot M_{1}(x)\right),\left(\mu M_{2} \cdot(y)\right)\right]
$$

So that obtaining the possibilities (14):

$$
V .\left(M_{2} \cdot \geq M_{.1}\right)=\left\{\begin{array}{cc}
1 & \text { if } . m_{2} \cdot \geq \cdot m_{1} \\
0 & \text { if } \cdot l_{1} \cdot \geq l_{2} \\
& \frac{l_{1}-u_{2}}{\left(m_{2 \cdot}-u_{2}\right) \cdot-\left(m_{1}-l_{1}\right)}
\end{array}\right.
$$

The next step is to calculate the defuzzification of the ordinate (d ') and the weight of the vector (V). Before calculating vector weight values, the first thing to do is calculate the value of defuzzification ordination. To calculate the ordinate defuzzification can use (15).

$$
d^{n}\left(A_{i}\right)=\min V\left(S_{i} \geq S_{k}\right)
$$
with (16)

The next step after obtaining the defuzzification ordinate is to calculate the vector weight value

$$
W^{n}=\left(d^{n}\left(A_{1}\right), d^{n}\left(A_{2}\right), d^{n}\left(A_{3}\right), \ldots \ldots, d^{n}\left(A_{i}\right)\right)^{T}
$$

where $\mathrm{Ai}=1,2, \ldots \mathrm{n}$ is a fuzzy vector.

After the vector weight value is known, the next step is to normalize the value of fuzzy vector weight (W) using (17).

$$
w=\left(d\left(A_{1}\right), d\left(A_{2}\right), d\left(A_{3}\right), \ldots \ldots, d\left(A_{n}\right)\right)^{T}
$$

The Technique for Order Preference by Similarity to Ideal Solution (TOPSIS) is a technical method for order preference with similarity to an ideal solution algorithm [36]. TOPSIS was first introduced by C.LHwang and K.Yoon in 1981 [42, 43]. In the case of the Multi-Criteria Decision Making (MCDM) many ranking methods can be used, one of which is a TOPSIS method [44]. MCDM was developed to provide solutions in the decision making the process [45]. There are five steps in the TOPSIS method [46, 47], namely: 
Step 1: Calculate the normalized decision matrix (18).

$$
r_{a b}=\frac{x_{a b}}{\sqrt{\sum_{i=1}^{m} x_{a b}^{2}}}, a=1,2,3 \ldots, m, b=1,2,3 \ldots, n
$$

Step 2: Calculate the weighted normalized decision matrix (19).

$$
v_{\mathrm{ab}}=w_{b} \cdot r_{a b}, \mathrm{a}=1,2,3, \ldots \mathrm{m}, \mathrm{b}=1,2,3, \ldots \mathrm{n}
$$

$w_{b}$ is the weight of the $b$ th criterion.

Step 3: Calculate the positive ideal solutions $A^{+}$and negative ideal solutions $A^{-}(20)$.

$$
\begin{aligned}
& \mathrm{A}^{+}=\left\{v_{1}^{+}, v_{2}^{+} \ldots v_{\mathrm{n}}^{+}\right\} \\
& \mathrm{A}^{-}=\left\{v_{1}^{-}, v_{2}^{-} \ldots v_{\mathrm{n}}^{-}\right\}
\end{aligned}
$$

Step 4: Using the Euclidean n-dimensional distance method do the calculation of the size of the separation of each alternative from the ideal solution $\left(\mathrm{D}_{\mathrm{a}}^{+}\right)$and separation of each alternative from the negative-ideal solution $\left(\mathrm{D}_{\mathrm{a}}^{-}\right)(21)$.

$$
\begin{aligned}
& D_{\mathrm{a}}^{-}=\sqrt{\sum_{\mathrm{b}=1}^{\mathrm{n}}\left(v_{\mathrm{ab}}-v_{\mathrm{b}}^{-}\right)^{2}} \\
& \mathbf{D}_{\mathrm{a}}^{+}=\sqrt{\sum_{\mathrm{b}=1}^{\mathrm{n}}\left(v_{\mathrm{ab}}-v_{\mathrm{b}}^{+}\right)^{2}}
\end{aligned}
$$

Step 5: Determine the preference value with (22).

$$
C_{a}=\frac{D_{a}^{-}}{\left(D_{a}^{+}+D_{a}^{-}\right)}
$$

Step 6 : Ranking the alternatives from largest to lowest preference value.

\subsection{Taxpayer Supervision Priorities}

After finding the algorithm with the best performance classification, the taxpayers are chosen as the priority of supervision. Based on the level of taxpayer compliance, the priority of taxpayers supervision is taxpayers who are at the level of compliance with the order of formal and material non-compliant taxpayers, formal compliant taxpayers, material compliant taxpayers, and formal and material compliant taxpayers.

This study uses the results of taxpayer data from the best algorithm classification with a formal and material non-compliant taxpayers goal as a role model because the priority taxpayers supervision has the same method for other levels of compliance. Twenty-five dataset variables are criteria for determining taxpayers supervision priorities. The results of taxpayer data from the best classification algorithm are the alternative to rank based on these Twenty-five criteria. Fuzzy AHP is used to give weight criteria and TOPSIS is used to rank alternatives. The flow of taxpayers supervision priorities determine the priority of taxpayers be supervised in this study as shown in Figure 4.

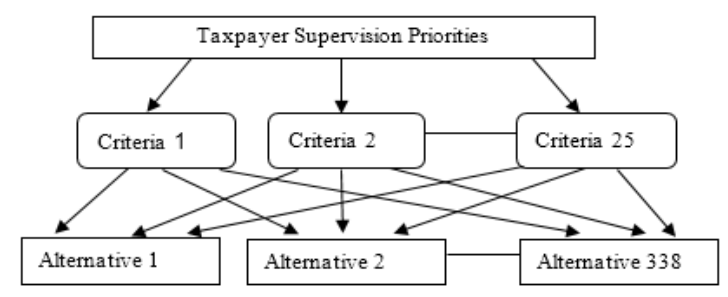

Figure 4. Hierarchy of purpose taxpayers supervision priorities 


\section{RESULTS AND DISCUSSION}

The results of the preprocessing process, normality test, and correlation test in this study produce dataset variables as shown in Table 1.

Table 1. The Variables of The Research Dataset

\begin{tabular}{|c|c|c|c|}
\hline No & Variable & Description & Type \\
\hline 1 & PKP_Status & Yes $=$ Taxpayers are taxable entrepreneurs, No $=$ Non-taxable entrepreneurs & Nominal \\
\hline 2 & Type_of_taxpayer & Badan $=$ Corporate taxpayer, $\mathrm{OP}=$ Individual taxpayer & Nominal \\
\hline 3 & Sector & The sector code of Taxpayer business & Nominal \\
\hline 4 & Late_Report & Late Amount of Report in one tax year & Numeric \\
\hline 5 & Not_Report & Amount Not Reported in one tax year & Numeric \\
\hline 6 & Late_to_pay & Late Pay Amount in one tax year & Numeric \\
\hline 7 & Arrears & Arrears Value of SKPKB for annual tax returns that have not been paid off & Numeric \\
\hline 8 & Turnover & Turnover & Numeric \\
\hline 9 & VAT & Value Added Tax (VAT) with MAP Code $=411211$ & Numeric \\
\hline 10 & Fiscal_Net_Income & Value of Fiscal Net Income & Numeric \\
\hline 11 & $\mathrm{PKP}--$ & Value of Taxable Income & Numeric \\
\hline 12 & Compensation & Value of Compensation for Losses & Numeric \\
\hline 13 & Income_Tax_payable & Value of Income Tax payable & Numeric \\
\hline 14 & PPh29_payment & $\begin{array}{l}\text { Value of Income Tax Article } 29 \text { payment with MAP Code }=411125 \text { or } 411126 \text { with payment } \\
\text { type code }=200\end{array}$ & Numeric \\
\hline 15 & Installment_Ps125 & The instalment amount of Article 25 Income Tax per month & Numeric \\
\hline 16 & Psl25_Payment & $\begin{array}{l}\text { Value of Income Tax Article } 29 \text { payment with MAP Code }=411125 \text { or } 411126 \text { with payment } \\
\text { type code }=100\end{array}$ & Numeric \\
\hline 17 & HPP & Cost of goods sold & Numeric \\
\hline 18 & DPP_Peng_TB & Basic Imposition of Taxes Transfer of Rights to Land and/or Buildings & Numeric \\
\hline 19 & 42_TB_Payment & $\begin{array}{l}\text { Payment of Final PPh Article } 4 \text { paragraph (2) for the transfer of rights to land and/or } \\
\text { buildings with MAP Code }=411128 \text { with payment type code }=402\end{array}$ & Numeric \\
\hline 20 & DPP_Construction & Tax Base for construction business & Numeric \\
\hline 21 & DPP_PP46 & Basic Imposition of Certain Income Taxes (PP 46) & Numeric \\
\hline 22 & PP46_Payment & Payment of PP 46 with MAP Code $=411128$ and payment type code $=420$ & Numeric \\
\hline 23 & $\mathrm{GPM}^{-}$ & Gross Profit Margin & Numeric \\
\hline 24 & NPM & Net Profit Margin & Numeric \\
\hline 25 & CTTOR & Corporate Tax Turn Over Ratio & Numeric \\
\hline 26 & Tax_Compliance & Goals of this study & Nominal \\
\hline
\end{tabular}

This study uses the Weka version 3.8.1 tool to test dataset. The dataset in this study has 2424 data. The C4.5, Support Vector Machine (SVM), K-Nearest Neighbor (KNN), Naive Bayes (NB), and Multilayer Perceptron (MLP) classification algorithms were tested and analyzed with a confusion matrix to show the performance classification of the algorithms. The test models used are 10-folds Cross-validation (M1) and Split Mode Percentage of $60 \%$ (M2). Table 2 shows a confusion matrix resulting from the 10-folds Crossvalidation (M1) testing method and Percentage.

Table 2. Confusion Matrix on M1 and on M2

\begin{tabular}{lcccccccccc}
\hline & \multicolumn{2}{c}{ C4.5 } & \multicolumn{2}{c}{ SVM } & \multicolumn{2}{c}{ KNN } & \multicolumn{3}{c}{ NB } & \multicolumn{2}{c}{ MLP } \\
& M1 & M2 & M1 & M2 & M1 & M2 & M1 & M2 & M1 & M2 \\
\hline Correctly Classified & 2371 & 950 & 2126 & 861 & 2081 & 841 & 1871 & 749 & 2141 & 875 \\
Incorrectly Classified & 53 & 23 & 298 & 112 & 343 & 132 & 553 & 224 & 283 & 98 \\
\hline
\end{tabular}

Split Mode 60\% (M2) method from each classification algorithm. Comparison of the classification results with the average value (A) of M1 and M2 is shown in Table 3.

Table 3. Comparison on M1 and on M2

\begin{tabular}{|c|c|c|c|c|c|c|c|c|c|c|c|c|c|c|c|}
\hline & \multicolumn{3}{|c|}{$\mathrm{C} 4.5$} & \multicolumn{3}{|c|}{ SVM } & \multicolumn{3}{|c|}{ KNN } & \multicolumn{3}{|c|}{ NB } & \multicolumn{2}{|c|}{ MLP } & \multirow[b]{2}{*}{ A } \\
\hline & M1 & M2 & A & M1 & M2 & A & M1 & M2 & A & M1 & M2 & A & M1 & M2 & \\
\hline Precision & 0.98 & 0.98 & 0.98 & 0.88 & 0.89 & 0.89 & 0.86 & 0.87 & 0.86 & 0.74 & 0.72 & 0.73 & 0.88 & 0.90 & 0.89 \\
\hline Recall & 0.98 & 0.98 & 0.98 & 0.88 & 0.89 & 0.88 & 0.86 & 0.86 & 0.86 & 0.77 & 0.77 & 0.77 & 0.88 & 0.90 & 0.89 \\
\hline F-Score & 0.98 & 0.98 & 0.98 & 0.88 & 0.89 & 0.88 & 0.86 & 0.86 & 0.86 & 0.75 & 0.74 & 0.75 & 0.88 & 0.90 & 0.89 \\
\hline Accuracy & 97.81 & 97.64 & 97.73 & 87.71 & 88.49 & 88.10 & 85.85 & 86.43 & 86.14 & 77.19 & 76.98 & 77.09 & 88.33 & 89.93 & 89.13 \\
\hline Time (seconds) & 0.11 & 0.13 & 0.12 & 3.34 & 3.04 & 3.19 & 0.00 & 0.00 & 0.00 & 0.05 & 0.02 & 0.04 & 72.67 & 69.37 & 71.02 \\
\hline
\end{tabular}


There are two phases, that are Fuzzy AHP and TOPSIS. Fuzzy AHP is used to obtain fuzzy vector weights based on the criteria of Accuracy (C1), F-Score (C2), and Time required (C3) whereas TOPSIS is used to determine the rank of all alternatives based on the largest preference value. The alternatives to determine the best algorithm are C4.5 (A1), SVM (A2), KNN (A3), NB (A4) and MLP (A5). The initial phases make a comparison of AHP criteria matrix from each criterion and make a comparison matrix of fuzzy AHP criteria and calculate the value of fuzzy Synthesis (Si) using (10) as Table 4.

Table 4. Comparison Matrix of Each Criterion and Value of $\mathrm{Si}$

\begin{tabular}{|c|c|c|c|c|c|c|c|c|c|c|c|c|}
\hline \multirow{2}{*}{$\mathrm{C}$} & \multicolumn{3}{|c|}{$\mathrm{C} 1$} & \multicolumn{3}{|c|}{$\mathrm{C} 2$} & \multicolumn{3}{|c|}{$\mathrm{C} 3$} & \multicolumn{3}{|c|}{ Synthesis Value } \\
\hline & $\mathrm{L}$ & $\mathrm{M}$ & $\mathrm{U}$ & $\mathrm{L}$ & $\mathrm{M}$ & $\mathrm{U}$ & $\mathrm{L}$ & $\mathrm{M}$ & $\mathrm{U}$ & $\mathrm{L}$ & $\mathrm{M}$ & $\mathrm{U}$ \\
\hline $\mathrm{C} 1$ & 1.0 & 1.0 & 1.0 & 0.5 & 1.0 & 1.5 & 1.0 & 1.5 & 2.0 & 0.20 & 0.38 & 0.63 \\
\hline $\mathrm{C} 2$ & 0.7 & 1.0 & 2.0 & 1.0 & 1.0 & 1.0 & 1.0 & 1.5 & 2.0 & 0.21 & 0.38 & 0.70 \\
\hline $\mathrm{C} 3$ & 0.5 & 0.7 & 1.0 & 0.5 & 0.7 & 1.0 & 1.0 & 1.0 & 1.0 & 0.16 & 0.25 & 0.42 \\
\hline
\end{tabular}

The next steps calculate the degree of possibility by using (13) and calculate the ordinate defuzzification value (d') using (15). The results are shown in Table 5. The final steps of Fuzzy AHP calculate Weight Vector values using (16) and normalize the value of the fuzzy Weight Vector using (17). The results are shown in Table 6.

Table 5. Degree of Possibility and Defuzzification Ordinate

\begin{tabular}{cccc}
\hline Criteria & Degree of possibility & Summary Of Degree & $\mathrm{d}^{\prime}$ \\
\hline \multirow{2}{*}{$\mathrm{C} 1$} & $\mathrm{C} 1>=\mathrm{C} 2$ & 1 & 1 \\
& $\mathrm{C} 1>=\mathrm{C} 3$ & 1.365 & \\
$\mathrm{C} 2$ & $\mathrm{C} 2>=\mathrm{C} 1$ & 1 & 1 \\
& $\mathrm{C} 2>=\mathrm{C} 3$ & 1.303 & \\
$\mathrm{C} 3$ & $\mathrm{C} 3>=\mathrm{C} 1$ & 0.636 & 0.622 \\
& $\mathrm{C} 3>=\mathrm{C} 2$ & 0.622 & \\
\hline
\end{tabular}

Table 6. Value of The Weight Vector

\begin{tabular}{ccc}
\hline Criteria & $\mathrm{W}^{\prime}$ & $\mathrm{W}$ \\
\hline $\mathrm{C} 1$ & 1 & 0.381 \\
$\mathrm{C} 2$ & 1 & 0.381 \\
$\mathrm{C} 3$ & 0.622 & 0.237 \\
\hline
\end{tabular}

After obtaining the weight of each criterion as in Table 6, the second phases rank alternative data to determine the best algorithm using the TOPSIS method. The first steps of the TOPSIS method create Alternative Data Normalization Matrix using (18) and create the Alternative Data Normalization Matrix using (19) based on the weight vector as shown in Table 6. The results of the Alternative Data Normalization Matrix and The Weighted Alternative Data Normalization Matrix are shown in Table 7.

Table 7. Alternative Data Normalization Matrix and The Weighted Alternative Data Normalization Matrix

\begin{tabular}{ccccccc}
\hline \multirow{2}{*}{ Alternative } & \multicolumn{3}{c}{ Normalization Matrix } & \multicolumn{3}{c}{ Weighted Normalization Matrix } \\
\cline { 2 - 7 } & $\mathrm{C} 1$ & $\mathrm{C} 2$ & $\mathrm{C} 3$ & $\mathrm{C} 1$ & $\mathrm{C} 2$ & $\mathrm{C} 3$ \\
\hline A1 & 0.497 & 0.501 & 0.002 & 0.19 & 0.191 & 0 \\
A2 & 0.448 & 0.45 & 0.045 & 0.171 & 0.172 & 0.011 \\
A3 & 0.438 & 0.439 & 0 & 0.167 & 0.168 & 0 \\
A4 & 0.392 & 0.383 & 0.001 & 0.15 & 0.146 & 0 \\
A5 & 0.454 & 0.455 & 0.999 & 0.173 & 0.173 & 0.237 \\
\hline
\end{tabular}

The next steps calculate the value of Positive Ideal Solutions Matrix and Negative Ideal Solutions Matrix using (20). The results of Positive Ideal Solutions Matrix and Negative Ideal Solutions Matrix are shown in Table 8. The value of Positive Ideal Solutions Matrix and Negative Ideal Solutions Matrix as shown in Table 8 are used to calculate Alternative Distance values using (21) and to calculate the preference values of each alternative using (22) as shown in Table 9. The final results of TOPSIS method rank preference values based on the largest preference value as shown in Table 10.

Table 8. Positive Ideal Solutions Matrix and Negative Ideal Solutions Matrix

\begin{tabular}{lccc}
\hline Alternative & C1 & C2 & C3 \\
\hline A+ & 0.19 & 0.191 & 0 \\
A- & 0.15 & 0.146 & 0.237 \\
\hline
\end{tabular}

Table 9. Alternative Distance and Value of Preference

\begin{tabular}{cccc}
\hline Alternative & Distance $+(\mathrm{D}+)$ & Distance $-(\mathrm{D}-)$ & Preference \\
\hline A1 & 0.0000 & 0.2449 & 0.998 \\
A2 & 0.0000 & 0.2280 & 0.887 \\
A3 & 0.0447 & 0.2366 & 0.880 \\
A4 & 0.0632 & 0.2366 & 0.797 \\
A5 & 0.2366 & 0.0447 & 0.131 \\
\hline
\end{tabular}


Table 10. Ranking Alternative

\begin{tabular}{ccc}
\hline Ranking & Alternative & Preference \\
\hline 1 & A1 & 0.998 \\
2 & A2 & 0.887 \\
3 & A3 & 0.880 \\
4 & A4 & 0.797 \\
5 & A5 & 0.131 \\
\hline
\end{tabular}

Table 10 shows that the $\mathrm{C} 4.5$ (A1) is the best performance classification because it has the largest preference. After finding the best algorithm, the next steps determine the priority of the taxpayer be supervised. The priority of taxpayers in this study is divided into two phases, namely Fuzzy AHP to obtain fuzzy vector weights and TOPSIS to rank all alternatives based on the largest preference value. The criterias for obtaining fuzzy vector weights are PKP_Status (C1), Type_of_taxpayer (C2), Sector (C3), Late_Report (C4), Not_Report (C5), Late_to_pay (C6), Arrears (C7), Turnover (C8), VAT (C9), Fiscal_Net_Income (C10), PKP (C11), Compensation (C12), Income_Tax_payable (C13), PPh29_payment (C14), Installment_Psl25 (C15), Psl25_Payment (C16), HPP (C17), DPP_Peng_TB (C18), 42_TB_Payment (C19), DPP_Construction (C20), DPP_PP46 (C21), PP46_Payment (C22), GPM (C23), NPM (C24), CTTOR (C25). This study ranks the priority of taxpayer's from class/goal formal and material non-compliant taxpayers data. It is the results of the best algorithm. The formal and material non-compliant taxpayers are 338 data. The first steps determining the priority of taxpayers to be supervised make a comparison matrix of AHP criteria as shown in Table 11.

The next steps make a comparison matrix of fuzzy AHP criteria with TFN scale and calculate fuzzy Synthesis (Si) using (11) based on Table 11. The values of fuzzy Synthesis are shown in Table 12. The next steps calculate the degree of possibility using (13) and calculate the ordinate defuzzification values (d ') using (15). The next steps calculate the vector weight values using (16) and normalize the values of the fuzzy Weight Vector using (17) as shown in Table 13.

Table 11. Comparison Matrix of Each Criterion

\begin{tabular}{|c|c|c|c|c|c|c|c|c|c|c|c|c|c|c|c|c|c|c|c|c|c|c|c|c|c|}
\hline & 01 & 02 & $\mathrm{C} 03$ & C04 & $\mathrm{C} 05$ & C06 & $\mathrm{C} 07$ & $\mathrm{C} 08$ & $\mathrm{C} 09$ & $\mathrm{C} 10$ & C11 & $\mathrm{C} 12$ & C13 & C14 & C15 & C16 & C17 & C18 & C19 & $\mathrm{C} 20$ & $\mathrm{C} 21$ & $\mathrm{C} 22$ & $\mathrm{C} 23$ & C24 & \\
\hline $\mathrm{C} 01$ & 0 & 5.0 & 3.0 & 3.0 & 3.0 & 4.0 & 0.1 & 0.3 & 0.2 & 0.3 & 0.3 & 0.3 & 0.3 & 0.2 & 3.0 & 0.2 & 0.3 & 3.0 & 0.2 & 3.0 & 03 & 02 & 0.2 & 0.2 & \\
\hline & & & & & & & & & & & & & & & & & & & & & & & & & \\
\hline & 3 & 3 & 0 & .0 & 0 & 0 & 0.1 & 3 & 0.2 & 4.0 & 0. & 0. & 0.3 & 0.2 & 3. & 0. & 0. & 0. & & .3 & .3 & & .2 & .2 & .3 \\
\hline $\mathrm{C} 04$ & 3 & 0.3 & 0.3 & 1.0 & .5 & 0 & 0.1 & 0.3 & 0.3 & 0.3 & 0.3 & 0. & 0.3 & 0.3 & 0. & 0 & 0. & 0.5 & 0. & 0.5 & 0.5 & & 0.3 & 0.3 & 0.3 \\
\hline & 3 & 3 & 3 & 2.0 & .0 & 0 & 0.1 & 0.3 & 0.3 & 0.3 & 0.3 & 0. & 0.3 & 0.3 & 0.3 & 0. & 0.3 & 0.5 &.. & 0.5 & 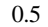 & & 1.3 & 0.3 & 0.3 \\
\hline 06 & 3 & 3 & 3 & .0 & 5 & & 1 & 3 & 0.3 & 0.3 & 0.3 & 0.5 & 0.3 & 0.3 & 0.3 & 0.3 & 0.3 & 0.5 & ? & 0.5 & .5 & & .3 & 0.3 & 0.3 \\
\hline & 0 & .0 & .0 & 7.0 & & & & & 30 & & 5. & & 5.0 & 3.0 & 4.0 & & & & & ( & & & ( & .0 & .0 \\
\hline & & .0 & & & & & & & & & & & 4. & & & & & & & & & & & .3 & 0.3 \\
\hline & & & & & & & & & & & & & & & & & & & & & & & & 3.0 & 2.0 \\
\hline & & & & & & & & & & & & & & & & & & & & & & & & .3 & 0.3 \\
\hline & & & & & & & & & & & & & & & & & & & & & & & & .3 & 0.3 \\
\hline & & & & & & & & & & & & & & & & & & & & & & & & .3 & 0.3 \\
\hline & & & & & & & & & & & & & & & & & & & & & & & & & 0.3 \\
\hline & & & & & & & & & & & & & & & & & & & & & & & & .0 & 2.0 \\
\hline & & & & & & & & & & & & & 2 & & & & & & & & & & & ).3 & 0.3 \\
\hline & & & & & & & & & & & & & 3 & 1 & 3 & & & & & & & & & .0 & 2.0 \\
\hline & & & & & & & & & & & & & 3. & 0. & 3 & & & & & & & & & .3 & 0.3 \\
\hline & & & & & & & & & & & & & 2. & 0. & 0. & & & & & & & & ).3 & 0.3 & 0.3 \\
\hline & & & & & & & & & & & & & 3. & 1. & & & & & & & & & & 3.0 & 2.0 \\
\hline & & & & & & & & & & & & & 2. & & & & & & & & & & .3 & 0.3 & 0.3 \\
\hline & & & & & & & & & & & & & 3. & & & & & & & & & & .3 & .3 & 0.3 \\
\hline & & 5 & & & & & & & & & 3. & & 3. & & 3 & & & & & & & & .0 & 3.0 & 2.0 \\
\hline & & & & 3.0 & 3. & & & & & & & & 3. & & & & & & & & & & .0 & .5 & 0.3 \\
\hline & 0 & 5.0 & 5.0 & 4.0 & 4.0 & 4.0 & & 3.0 & & & 3. & 3. & 3.0 & 0.3 & 3.0 & & 3. & & & 3.0 & & & 2.0 & 1.0 & 0.5 \\
\hline 25 & .0 & 5.0 & 4.0 & 3.0 & 3.0 & 3.0 & 0.5 & 3.0 & 0.5 & 3.0 & 3.0 & 3.0 & 3.0 & 0.5 & 3.0 & 0.5 & 3.0 & 3.0 & 0.5 & 3.0 & 3.0 & 0.5 & 3.0 & 2.0 & 1.0 \\
\hline
\end{tabular}

Table 12. Value of $\mathrm{Si}$

\begin{tabular}{llllllllllllllllllllllllllllllllll}
$\mathrm{C} 01$ & $\mathrm{C} 02$ & $\mathrm{C} 03$ & $\mathrm{C} 04$ & $\mathrm{C} 05$ & $\mathrm{C} 06$ & $\mathrm{C} 07$ & $\mathrm{C} 08$ & $\mathrm{C} 09$ & $\mathrm{C} 10$ & $\mathrm{C} 11$ & $\mathrm{C} 12$ & $\mathrm{C} 13$ & $\mathrm{C} 14$ & $\mathrm{C} 15$ & $\mathrm{C} 16$ & $\mathrm{C} 17$ & $\mathrm{C} 18$ & $\mathrm{C} 19$ & $\mathrm{C} 20$ & $\mathrm{C} 21$ & $\mathrm{C} 22$ & $\mathrm{C} 23$ & $\mathrm{C} 24$ & $\mathrm{C} 25$ \\
\hline
\end{tabular} \begin{tabular}{llllllllllllllllllllllllllll}
\hline $\mathrm{L}$ & 0.02 & 0.02 & 0.02 & 0.01 & 0.01 & 0.01 & 0.05 & 0.03 & 0.03 & 0.02 & 0.02 & 0.01 & 0.02 & 0.03 & 0.02 & 0.03 & 0.02 & 0.02 & 0.03 & 0.02 & 0.02 & 0.03 & 0.03 & 0.03 & 0.03
\end{tabular} $\begin{array}{lllllllllllllllllllllllllll}\mathrm{M} & 0.03 & 0.03 & 0.03 & 0.03 & 0.03 & 0.03 & 0.08 & 0.05 & 0.06 & 0.04 & 0.04 & 0.03 & 0.04 & 0.05 & 0.03 & 0.05 & 0.04 & 0.03 & 0.05 & 0.03 & 0.03 & 0.05 & 0.05 & 0.05 & 0.05\end{array}$ \begin{tabular}{lllllllllllllllllllllllllll}
$\mathrm{U}$ & 0.05 & 0.05 & 0.05 & 0.05 & 0.05 & 0.05 & 0.13 & 0.08 & 0.10 & 0.07 & 0.07 & 0.05 & 0.07 & 0.09 & 0.06 & 0.09 & 0.08 & 0.06 & 0.09 & 0.06 & 0.06 & 0.09 & 0.09 & 0.09 & 0.10 \\
\hline
\end{tabular}

Table 13. Value of The Weight Vector \begin{tabular}{lllllllllllllllllllllllllllllllll}
\hline & C01 & C02 & C03 & C04 & C05 & C06 & C07 & C08 & C09 & C10 & C11 & C12 & C13 & C14 & C15 & C16 & C17 & C18 & C19 & C20 & C21 & C22 & C23 & C24 & C25 \\
\hline W' & 0.13 & 0.07 & 0.09 & 0.12 & 0.12 & 0.10 & 1.00 & 0.51 & 0.72 & 0.32 & 0.36 & 0.07 & 0.36 & 0.62 & 0.17 & 0.61 & 0.44 & 0.18 & 0.64 & 0.17 & 0.25 & 0.61 & 0.56 & 0.59 & 0.63
\end{tabular}

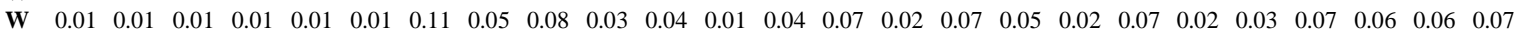


After obtaining the weights of each criterion as shown in Table 13, the second phases rank alternative data using the TOPSIS method. The initial steps of the TOPSIS method create the alternative data normalization matrix using (18) and create the Weighted Alternative Data Normalization Matrix using (19). The results of the Weighted Alternative Data Normalization Matrix are used to calculate the values of Positive Ideal Solutions Matrix and Negative Ideal Solutions Matrix using (20) as shown in Table 14.

Table 14. Positive Ideal Solutions Matrix and Negative Ideal Solutions Matrix

\begin{tabular}{llllllllllllllllllllllllllllllllllllll}
\hline & C01 & C02 & C03 & C04 & C05 & C06 & C07 & C08 & C09 & C10 & C11 & C12 & C13 & C14 & C15 & C16 & C17 & C18 & C19 & C20 & C21 & C22 & C23 & C24 & C25 \\
\hline A+ & 0.00 & 0.00 & 0.00 & 0.00 & 0.01 & 0.00 & 0.08 & 0.02 & 0.05 & 0.02 & 0.02 & 0.01 & 0.02 & 0.05 & 0.01 & 0.03 & 0.01 & 0.01 & 0.06 & 0.01 & 0.02 & 0.04 & 0.01 & 0.02 & 0.03 \\
A- & 0.00 & 0.00 & 0.00 & 0.00 & 0.00 & 0.00 & 0.00 & 0.00 & 0.00 & 0.00 & 0.00 & 0.00 & 0.00 & 0.00 & 0.00 & 0.00 & 0.00 & 0.00 & 0.00 & 0.00 & 0.00 & 0.00 & 0.00 & -0.01 & 0.00 \\
\hline
\end{tabular}

The values of Positive Ideal Solutions Matrix and Negative Ideal Solutions Matrix as shown in Table 14 are used to calculate Alternative Distance values using (21). After that, the preference values of each alternative are calculated using (22). The final results determine the priority of taxpayers be supervised as shown in Table 15 which rank alternatives based on the largest reference values. A taxpayer with Alternative A233 is priority number one taxpayer to be supervised while the taxpayer with alternative A051 is the last priority taxpayer.

Table 15. Ranking Alternative

\begin{tabular}{ccc}
\hline Ranking & Alternative & Preference \\
\hline 1 & A233 & 0.433 \\
2 & A163 & 0.362 \\
3 & A240 & 0.330 \\
4 & A316 & 0.326 \\
5 & A151 & 0.304 \\
. &. &. \\
. &. &. \\
. &. &. \\
337 & A035 & 0.044 \\
338 & A051 & 0.036 \\
\hline
\end{tabular}

\section{CONCLUSION}

Table 10 shows that the $\mathrm{C} 4.5$ (A1) algorithm is the best performance classification to classify taxpayer compliance based on this study dataset with a preference value of 0.998 whereas the MLP (A5) algorithm is the lowest classification algorithm with a preference value of 0.131 . Table 15 shows that fuzzy AHP and TOPSIS methods rank taxpayer priorities for supervision at each level of compliance from the best algorithm classification results. Alternative taxpayer A233 is the top priority taxpayer with preference value 0.433 whereas alternative taxpayer A051 is the lowest priority taxpayer with preference value 0.036 .

Further studies can be developed by expanding data sources for data mining selection. Tax avoidance can be known and detected as early as possible if the criteria used are complex and current with tax avoidance behavior.

\section{ACKNOWLEDGEMENTS}

Authors give a deep thanks to Institut Teknologi Sepuluh Nopember for supporting the study.

\section{REFERENCES}

[1] S. Kafkalas, P. Kalaitzidakis, and V. Tzouvelekas, "Tax evasion and public expenditures on tax revenue services in an endogenous growth model," Eur. Econ. Rev., 2014.

[2] R. F. Rahmat, S. Purnamawati, H. Saito, M. F. Ichwan, and T. M. Lubis, "Android-based automatic detection and measurement system of highway billboard for tax calculation in Indonesia," IJEECS, vol. 14, no. 2, pp. 877-886, 2019.

[3] E. Rahimikia, S. Mohammadi, T. Rahmani, and M. Ghazanfari, "Detecting corporate tax evasion using a hybrid intelligent system: A case study of Iran," Int. J. Account. Inf. Syst., vol. 25, pp. 1-17, 2017.

[4] F. Tian et al., "Mining suspicious tax evasion groups in big data," IEEE Trans. Knowl. Data Eng., vol. 28, no. 10, pp. 2651-2664, 2016.

[5] M. S. Rad and A. Shahbahrami, "High performance implementation of tax fraud detection algorithm," 2015 Signal Process. Intell. Syst. Conf. Sp. 2015, pp. 6-9, 2016. 
[6] P. Castellón González and J. D. Velásquez, "Characterization and detection of taxpayers with false invoices using data mining techniques," Expert Syst. Appl., vol. 40, no. 5, pp. 1427-1436, 2013.

[7] S. Mohamed and A. Ezzati, "A data mining process using classification techniques for employability prediction," IJEECS, vol. 14, no. 2, pp. 1025-1029, 2019.

[8] Arisman, "Nitric Oxide Chemistry and Velocity Slip Effects in Hypersonic Boundary Layers," Thesis, vol. 25, no. 1, pp. 1-64, 2014.

[9] V. Kotu and B. Deshpande, Predictive Analytics and Data Mining: Concepts and Practice with RapidMiner. 2014.

[10] S. García, J. Luengo, and F. Herrera, "Preface," Intell. Syst. Ref. Libr., vol. 72, 2015.

[11] H. Jiawei, M. Kamber, J. Han, M. Kamber, and J. Pei, Data Mining: Concepts and Techniques. 2012.

[12] Z. Hanusz and J. Tarasińska, "Normalization of the Kolmogorov-Smirnov and Shapiro-Wilk tests of normality," Biometrical Lett., vol. 52, no. 2, pp. 85-93, 2015.

[13] C. Dissanayaka, H. Abdullah, B. Ahmed, T. Penzel, and D. Cvetkovic, "Classification of healthy subjects and insomniac patients based on automated sleep onset detection," in IFMBE Proceedings, 2016, vol. 56, pp. 188-192.

[14] L. Liu, "Biostatistical Basis of Inference in Heart Failure Study," Hear. Fail. Epidemiol. Res. Methods, pp. 43-82, 2017.

[15] A. Priya and E. Meenakshi, "Detection of phishing websites using C4.5 data mining algorithm," RTEICT 2017 2nd IEEE Int. Conf. Recent Trends Electron. Inf. Commun. Technol. Proc., vol. 2018-Janua, pp. 1468-1472, 2018.

[16] M. Fikri and R. Sarno, "A comparative study of sentiment analysis using SVM and SentiWordNet," IJEECS, vol. 13, no. 3, pp. 902-909, 2019.

[17] P. A. Abhang, B. W. Gawali, and S. C. Mehrotra, Introduction to EEG- and Speech-Based Emotion Recognition. 2016.

[18] T. Cohen and D. Widdows, "Geometric Representations in Biomedical Informatics: Applications in Automated Text Analysis," in Methods in Biomedical Informatics: A Pragmatic Approach, 2013, pp. 99-139.

[19] F. Chen, Z. Ye, C. Wang, L. Yan, and R. Wang, "A feature selection approach for network intrusion detection based on tree-seed algorithm and k-nearest neighbor," Proc. 2018 IEEE 4th Int. Symp. Wirel. Syst. within Int. Conf. Intell. Data Acquis. Adv. Comput. Syst. IDAACS-SWS 2018, pp. 68-72, 2018.

[20] R. Dorajoo, J. Liu, and B. O. Boehm, "Genetics of type 2 diabetes and clinical utility," Genes (Basel)., vol. 6, no. 2, pp. 372-384, 2015.

[21] N. E. Karkalos and A. P. Markopoulos, Modeling of hard machining, vol. 1. Elsevier Ltd., 2017.

[22] S. I. Sabilla and R. Sarno, "Development of wavelet transforms to predict methane in chili using the electronic nose," Proceeding - ICAMIMIA 2017 Int. Conf. Adv. Mechatronics, Intell. Manuf. Ind. Autom., pp. 271-276, 2018.

[23] A. Meyer-Baese and J. J. Schmid Volker, "Pattern Recognition and Signal Analysis in Medical Imaging: Second Edition," Pattern Recognit. Signal Anal. Med. Imaging Second Ed., pp. 1-444, 2014.

[24] R. Nisbet, G. Miner, and K. Yale, "Model Evaluation and Enhancement," Handb. Stat. Anal. Data Min. Appl., pp. 215-233, 2018.

[25] M. Bramer, Principles of Data Mining. 2007.

[26] R. Sarno, D. R. Wijaya, and M. N. Mahardika, "Music fingerprinting based on bhattacharya distance for song and cover song recognition," IJECE, vol. 9, no. 2, pp. 1036-1044, 2019.

[27] U. Yudatama and R. Sarno, "Evaluation maturity index and risk management for it governance using Fuzzy AHP and Fuzzy TOPSIS (case Study Bank XYZ),” 2015 Int. Semin. Intell. Technol. Its Appl. ISITIA 2015 - Proceeding, pp. 323-327, 2015.

[28] C. C. Sun, "A performance evaluation model by integrating fuzzy AHP and fuzzy TOPSIS methods," Expert Syst. Appl., vol. 37, no. 12, pp. 7745-7754, 2010.

[29] I. Ertuğrul and N. Karakaşoğlu, "Comparison of fuzzy AHP and fuzzy TOPSIS methods for facility location selection," Int. J. Adv. Manuf. Technol., vol. 39, no. 7-8, pp. 783-795, 2008.

[30] K. A. Wiguna, R. Sarno, and N. F. Ariyani, “10.1109@ICTS.2016.7910305.pdf,” pp. 237-243, 2016.

[31] T. L. Saaty, The Analytic Hierarchy Process. 1980.

[32] N. Noradachanon and T. Senivongse, "Decision Model for Identity Management Product Selection Using Fuzzy AHP," pp. 269-275, 2017.

[33] T. L. Saaty, "Decision making with the analytic hierarchy process," Int. J. Serv. Sci., vol. 1, no. 1, p. 83, 2008.

[34] N. Saaludin, M. H. Ismail, B. C. Mat, and S. Harun, "Improving lecturers' evaluation score by using analytic hierarchy process (AHP): A case at Universiti Kuala Lumpur," IJEECS, vol. 15, no. 1, pp. 391-398, 2019.

[35] S. Pavani, L. K. Sharma, and H. S. Hota, "A group expert evaluation for teachers by integrating fuzzy AHP and TOPSIS models," in Proceedings of the 2013 IEEE International Conference in MOOC, Innovation and Technology in Education, MITE 2013, 2013, pp. 85-90.

[36] C. Science, E. M. Mohamed, B. Bouikhalene, F. Ouatik, S. Safi, and A. Info, "AHP and TOPSIS methods applied in the field of scientific," IJEECS, vol. 14, no. 3, pp. 1382-1390, 2019.

[37] S. Grazioso, M. Selvaggio, D. Marzullo, G. Di Gironimo, and M. Gospodarczyk, "ELIGERE: A fuzzy AHP distributed software platform for group decision making in engineering design," in IEEE International Conference on Fuzzy Systems, 2017.

[38] L. a. Zadeh, "Fuzzy sets," Inf. Control, vol. 8, no. 3, pp. 338-353, 1965.

[39] H. T. X. Chi and V. F. Yu, "Ranking generalized fuzzy numbers based on centroid and rank index," Appl. Soft Comput. J., vol. 68, pp. 283-292, 2018.

[40] S. A. Halim, S. Deris, and M. Z. M. Zaki, "Fuzzy AHP based design decision for Product Line architecture," 2014 8th. Malaysian Softw. Eng. Conf., pp. 119-124, 2014. 
[41] Z. Yan, "Estimating Quality of the Construction Engineering Project Using Fuzzy AHP Approach," in 2016 International Conference on Smart Grid and Electrical Automation (ICSGEA), 2016, pp. 98-101.

[42] G. Sophia and R. Sarno, "AHP-TOPSIS for analyzing job performance with factor evaluation system and process mining," TELKOMNIKA, vol. 17, no. 3, p. 1344, 2019.

[43] X. Li, D. Zhou, Z. Yang, J. Huang, K. Zhang, and Q. Pan, "UAV route evaluation algorithm based on CSA-AHP and TOPSIS,” 2017 IEEE Int. Conf. Inf. Autom. ICIA 2017, no. July, pp. 915-920, 2017.

[44] S. A. A. Alrababah, K. H. Gan, and T. P. Tan, "Comparative analysis of MCDM methods for product aspect ranking: TOPSIS and VIKOR," in 2017 8th International Conference on Information and Communication Systems, ICICS 2017, 2017, pp. 76-81.

[45] A. Cahyapratama and R. Sarno, "Application of Analytic Hierarchy Process (AHP) and Simple Additive Weighting (SAW) methods in singer selection process," 2018 Int. Conf. Inf. Commun. Technol. ICOIACT 2018, vol. 2018Janua, no. Mcdm, pp. 234-239, 2018.

[46] M. R. Sanjay, M. Jawaid, N. V. R. Naidu, and B. Yogesha, TOPSIS method for selection of best composite laminate. Elsevier, 2018.

[47] N. Ploskas and J. Papathanasiou, "A decision support system for multiple criteria alternative ranking using TOPSIS and VIKOR in fuzzy and nonfuzzy environments," Fuzzy Sets Syst., vol. 1, pp. 1-30, 2019.

\section{BIOGRAPHIES OF AUTHORS}

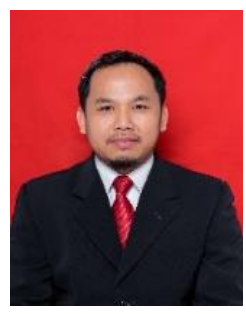

M. Jupri is now a second-year student of Department of Information Technology Management, Faculty of Business and Technology Management, Institut Teknologi Sepuluh Nopember. His current interests are in Data Mining, Decision Making, and Machine Learning

E-mail: m.jupri@gmail.com

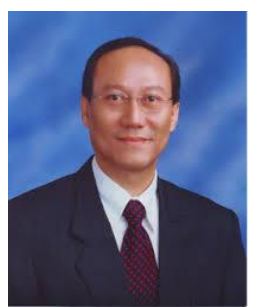

Riyanarto Sarno received M.Sc and Ph.D in Computer Science from the University of Brunswick Canada in 1988 and 1992. In 2003 he was promoted to a Full Professor. His teaching and research interests includes Internet of Things, Process Aware Information Systems, Intelligent Systems and Business Process Management.

E-mail: riyanarto@if.its.ac.id 